\title{
Estudio dialéctico de la economía social
}

\author{
(Dialectic study of the social economy)
}

\author{
Analaura Medina Conde ${ }^{1}$ \\ Instituto Tecnológico Superior de Tepexi de Rodríguez (México) \\ Uziel Flores Ilhuicatzi \\ Universidad de las Américas Puebla (México)
}

Sumario: I. Introducción. II. Tesis: Capitalismo-Neoliberalismo. III. Anti-Tesis. Socialismo-Comunismo. IV. Síntesis. Economía Social. V. Tesis: Capitalismo-Neoliberalismo en América Latina. VI. Anti-Tesis. Socialismo-Comunismo en América Latina. VII. Síntesis. Economía Social en América Latina. VIII. Características generales de la Economía Social. IX. Métodos y materiales. X. Resultados. XI. Conclusiones. XII. Fuentes documentales.

Summary: I. Introduction. II. Thesis: Capitalism-Neoliberalism. III. Anti-Thesis. Socialism-Communism. IV. Synthesis: Social economy. V. Thesis: Capitalism-Neoliberalism in Latin America. VI. Anti-Thesis: Socialism-Communism in Latin America. VII. Synthesis: Social Economy in Latin America. VIII. General characteristics of the Social Economy. IX. Methods and materials. X. Results. XI. Conclusions. XII. Documentary sources.

Resumen: En el presente documento se propone un marco terminológico y planteamiento teórico dialectico de la economía social, se desarrollan los ele-

1 Posdoctorado CONACYT en Derecho de la Empresa en la Universidad de Zaragoza, España, Doctorado en Derecho en argumentación jurídica y Maestría en Derecho Fiscal por el Centro de Estudios Jurídico Políticos de la Universidad Autónoma de Tlaxcala, Miembro del Sistema Nacional de investigadores (C), Perfil Deseable como Profesor-Investigador de Tiempo Completo PRODEP, Directora de Investigación en el Instituto de Ciencias Sociales y Humanidades y profesor Investigador de tiempo completo de la Universidad Tecnológica de la Mixteca hasta 2017, Profesor-Investigador del Instituto Tecnológico Superior de Tepexi de Rodríguez, Catedrática de Posgrado en Derecho en la UNAM.

2 Candidato a Doctor en Contabilidad y Finanzas en la Universidad de Zaragoza, España, Maestro en Administración y Licenciado en Contaduría Pública por la Facultad de Ciencias Económico Administrativas de la Universidad Autónoma de Tlaxcala, Perfil deseable como Profesor-Investigador de Tiempo Completo PRODEP, Profesor investigador de tiempo completo en la Universidad Tecnológica de la Mixteca hasta 2017, ProfesorInvestigador de la Universidad de las Américas Puebla. 
mentos dialecticos de la investigación, Tesis-Capitalismo-Neoliberalismo, Antitesis, socialismo-comunismo, Síntesis-Economía Social, se afirma que el método científico puede definirse como la «contrastación dialéctica entre la teoría y la práctica» por ello, siguiendo la línea metodológica se realiza el estudio del grado de aceptación de la economía social en Europa y Latinoamérica.

Palabras clave: Economía Social, Estudio Dialéctico, Ward.

Abstract: In this paper we propose a terminological framework and dialectical theoretical approach of social economy, the dialectical elements of research, Thesis-Capitalism-Neoliberalism, Anti-thesis, socialism-communism, synthesis-Social Economy, Scientific method can be defined as «dialectical contrast between theory and practice». Therefore, following the methodological line, the degree of acceptance of the social economy in Europe and Latin America is studied.

Keywords: Social Economy, Dialectical Study, Ward 


\section{Introducción}

El presente trabajo tiene como objetivo general realizar un estudio dialectico de la Economía Social, en la primera parte del trabajo, eminentemente teórica, se ha utilizado el método analítico-sintético Soldevilla, (1991), se propone un marco terminológico, conceptual y planteamiento teórico dialéctico.

El enfoque dialéctico materialista a decir de Matias \& Hernández, (2014) obedece a una lógica de sentido metodológico, cuya vigencia es indiscutible, la dialéctica materialista considera que el movimiento es ininterrumpido y que transcurre como proceso a través de diversas direcciones en una unidad de cambios progresivos y bruscos, de continuidad y ruptura, por lo que lo cuantitativo y lo cualitativo son considerados, no a modo de pares separados, sino de unidad dialéctica que se expresa en el contexto, en la relación concreta que los activa.

Engels textualmente indica: "La situación económica es la base, pero los distintos factores de la superestructura que sobre ella se levanta ejercen también su influencia sobre el curso de las luchas históricas y determinan predominantemente en muchos casos su forma. Es un juego mutuo de acción y reacción» (Engels, 1980). En la figura 1. Se presenta la causalidad dialéctica exógena de la economía Social:

\section{Figura 1. Causalidad dialéctica exógena}

\section{Tesis}

La mirada neoliberal se centra en una visión utilitaria de la persona, que debe someterse al funcionamiento libre de los mercados, que reduce la labor del Estado a su mínima expresión, y donde la cuestión social no tiene cabida ni preocupación real.

\section{Anti-tesis}

La mirada socialista, rompe los necesarios equilibrios macroeconómicos, sobredimensiona al Estado, al que incorpora a la producción de bienes y servicios, desvirtúa las políticas públicas de crecimiento y equidad, generando una política clientelar de corto plazo que no desarrolla al país y que retrocede en materia de disminución de la pobreza.

\section{Síntesis}

La economía social presenta una visión que se centra en la dignidad de las personas y el rol de las comunidades, como su orientación básica. Se trata de un modelo de desarrollo que salvaguarda los mínimos éticos necesarios para que toda persona pueda vivir dignamente.

Fuente: Elaboración propia con datos de (Gutenberg, 2010) 
En el siguiente apartado se desarrollan los elementos dialecticos de la investigación, Tesis-Capitalismo-Neoliberalismo, Anti-tesis, socialismo-comunismo, síntesis-Economía Social.

\section{Tesis: Capitalismo-Neoliberalismo}

Hurtado, (2010) afirma que Adam Smith, en la Riqueza de las Naciones señaló algunas de las ideas que conformarían la esencia del pensamiento económico liberal. Afirmó que los individuos, en sus actividades económicas, naturalmente se inclinaban por la búsqueda del interés personal, cuya atención era más útil para la sociedad que las actividades que específicamente buscaban satisfacer el interés social. El mejor remedio para la regulación de los precios era dejar que actuara la ley natural de la oferta y la demanda.

Bobbio, (1991) afirma que, como teoría económica, el liberalismo es partidario de la economía de mercado; como teoría política es simpatizante del Estado que gobierne lo menos posible o, del Estado mínimo (reducido al mínimo indispensable). El liberalismo como expresión del pensamiento y acción debe ser caracterizada para que incluya la diversidad y multiplicidad de ideas sin que se pierda su significación esencial como ideología.

Hurtado, (2010) sigue indicando que, si el futuro económico de los países dependía de la suerte que corrieran las actividades económicas particulares, lo mejor que podía hacer el Estado era limitar su acción a garantizar la libre acción de las fuerzas del mercado. El progreso era el resultado de mercados libres y competitivos, de la libre empresa, del libre cambio y del libre accionar de los individuos en la economía. Las libertades económicas eran vistas como un derecho natural de los seres humanos y el mejor incentivo para el progreso.

Sobre la base de este conjunto de creencias, Marques, (2015) afirma que el liberalismo clásico rechaza de plano cualquier tipo de reforma social basada en consideraciones de equidad y justicia distributiva, y rechaza todo tipo de interferencia estatal o gremial con las decisiones de los propietarios. Su idea es que, en general, la interferencia estatal (o gremial) no puede mejorar los resultados de la libre competencia. Por ello, la intervención es innecesaria (y suele ser perjudicial).

Hurtado, (2010) dice que doscientos años después, estas ideas fueron recogidas por el profesor de la Universidad de Chicago Milton Friedman, para el padre del liberalismo contemporáneo, el Estado debía limitarse a dotar a la sociedad de un marco jurídico que protegiera a los individuos y a sus actividades económicas, a fin de que operaran 
en libertad, para lo cual era necesario que constituyera instituciones que garantizaran el ejercicio efectivo de tal derecho.

«Luego de la segunda guerra mundial resulta obvio que la estructura del mercado ha cambiado sustancialmente respecto de la que imperaba en la época de Smith y Ricardo. La industria moderna está ahora poblada por corporaciones gigantes que tienden a sustituir a la pequeña empresa. Tanto es así, que Hayek asume el carácter imperfecto de la competencia, es decir, el hecho de que las empresas pueden imponer los precios de sus productos y disfrutar, al menos temporalmente, de beneficios monopólicos. Esto suscitó un problema para los nuevos defensores del mercado, ya que muchos (incluso en el seno mismo de las huestes liberales) consideraban al monopolio como socialmente perjudicial (y desde la propia teoría económica no existía una clara defensa de la competencia monopolística). Lo primero que salta a la vista es que la nueva estructura que adopta el mercado pone en entredicho la tesis de la soberanía del consumidor, que está en el centro del argumento pro-mercado de los austriacos. En condiciones de competencia monopolista, los productores no son tomadores de precios. Pueden decidir la magnitud de sus beneficios y operar a un nivel de actividad inferior al que resultaría óptimo desde el punto de vista social. La tesis de que todas las magnitudes de las variables económicas están determinadas por las decisiones de consumo ya no es sostenible, y el argumento moral anti-intervencionista ya no puede ser empleado Si el libre mercado continúa siendo defendible en las nuevas condiciones, se requieren otros argumentos para exhibir sus ventajas» (Marques, 2015: 6).

En los albores de la crisis financiera mundial de 2008 a decir de Palley, (2014) y el consecuente gran estancamiento, los eventos se van desfilando uno a uno ante Friedman, lo cual ha creado una esquizofrenia intelectual cuando dichos eventos hablan de lo acertado del viejo keynesianismo y, no obstante, la economía política de Friedman sigue siendo dominante entre la elite económica y política. Esa condición obstaculiza una reactivación teórica plena de la economía de Keynes, acarreando consigo graves consecuencias en la política económica.

«Para los pensadores clásicos del liberalismo económico la idea del bien común era el sustento sobre el que se fincaban sus principios, que pese a todas las críticas que se pudieran hacer, justificaba su orden económico hacia un fin enclavado en la comunidad» (Cruz, 2002).

Pero, ¿es posible referirse al bien común, o a una sociedad más justa y libre?, Boaventura, (2009) hace referencia a datos proporcionados en 1997 a 1999 respecto de que había 815 millones de personas 
desnutridas en el mundo: 777 millones en los países en vías de desarroIlo, 27 millones en los países que hacían la transición a las economías de mercado y 11 millones en los países industrializados. En el siglo XX murieron de hambre más personas que en cualquiera de los siglos anteriores. Un economista del banco mundial concluyó en un estudio de amplio espectro que cubre el $85 \%$ de la población mundial de 91 países, que el $1 \%$ más rico del mundo tiene ingresos equivalentes a los del $57 \%$ más pobre. Cuatro quintas partes de la población del mundo viven por debajo de lo que países en América del norte y Europa consideran la línea de pobreza.

«Desde 2015 , el $1 \%$ más rico de la población mundial posee más riqueza que el resto del planeta» (Foro Economico Mundial, 2015)

\section{Anti-Tesis. Socialismo-Comunismo}

La anti-tesis del capitalismo y del neoliberalismo es el socialismo y/o comunismo, sin embargo, como los indica Muñoz, (2015) actualmente los conceptos de socialismo y de comunismo se manejan como sinónimos, cosa que no debería ser. Karl Marx entendía el paso del capitalismo al socialismo y del socialismo al comunismo como producto del devenir histórico, es decir, como el resultado del desarrollo de las fuerzas productivas dentro de la sociedad que van alterando poco a poco las relaciones sociales de producción, atendiendo a la dialéctica, metodología utilizada en el presente documento de tesis.

Bunge afirma que:

«Durante la primera mitad del siglo XIX, florecieron en Francia e Inglaterra los llamados socialistas utópicos. Friedrich Engels destacó en particular a Charles Fourier, Henri de Saint Simon y Robert Owen. El falansterio, la utopía imaginada por Fourier, era una pequeña sociedad igualitaria en la que cada cual tenía su puesto fijo, con tareas predeterminadas: la de Fourier era una sociedad tan totalitaria como la sociedad teocrática a la que aspiraban los dirigentes de las religiones monoteístas y del hinduismo. Era lo que Popper llamó una sociedad cerrada: sin libertad y, por lo tanto, sin posibilidad de progresar, ya que las ideas originales nacen en cerebros privilegiados» (Bunge, 2010, pág. 21).

Para Martínez Heredia, (2008) este socialismo busca alcanzar los ideales de justicia social y de armonía universal prometidos por la modernidad y que nunca se han alcanzado; presupone un gran desarrollo económico, una gran liberación de los trabajadores y una democracia muy superior a la que hasta ahora se ha logrado en el capitalismo. 
Bunge, (2010) afirma «Adoptaré una definición de «socialismo» que creo congruente con todas las corrientes de izquierda. En una sociedad auténticamente socialista, los bienes y las cargas, los derechos y los deberes se distribuyen equitativamente. En otras palabras, el socialismo realiza el ideal de la justicia social» (2010).

Continúa diciendo Martínez Heredia, (2008) este socialismo, de ser alcanzado, garantizaría completamente las libertades individuales, tendría instituciones intermedias, contrapesos, control ciudadano, extinción progresiva de los poderes y productores libres. Una sociedad con estas características no la puede garantizar el capitalismo, por lo tanto, este debe ser erradicado y reemplazado por el socialismo.

Sin embargo, Bettelheim afirma:

El alcance real de la propiedad estatal depende de las relaciones reales existentes entre la masa de los trabajadores y el aparato estatal. Si este aparato está verdadera y concretamente dominado por los trabajadores (en lugar de hallarse sobre éstos y de dominarlos), la propiedad estatal es la forma jurídica de la propiedad social de los trabajadores; al contrario, si los trabajadores no dominan el aparato estatal, si éste es dominado por un cuerpo de funcionarios y administradores y escapa al control y a la dirección de las masas trabajadoras, es este cuerpo de funcionarios y administradores el que se convierte, efectivamente, en propietario (en el sentido de una relación de producción) de los medios de producción. Este cuerpo forma entonces una clase social (una burguesía estatal) en razón de las relaciones existentes entre él y los medios de producción, por una parte, y los trabajadores por la otra. Esta situación no implica, evidentemente, que esta clase consuma personalmente la totalidad del producto excedente, sino que dispone de éste según normas que son normas de clase, incluso si está obligado a dejar desempeñar un papel dominante al mercado y a los «criterios de rentabilidad» (Bettelheim, 1979, pág. 138)

En este contexto Valenzuela, (2006) afirma que en el mundo contemporáneo existe una noción muy extendida: el derrumbe de la URSS (y de sus similares) es equivalente al fracaso del socialismo y de la teoría marxista. El autor rechaza este punto de vista y argumenta en favor de: a) el sistema social que se derrumbó en la URSS no era socialista. Este carácter lo perdió antes de 1950; b) la teoría oficial imperante en la URSS representó una brutal deformación del marxismo original; c) el marxismo auténtico conserva su fuerte poder explicativo; d) las realidades del capitalismo contemporáneo obligan a seguir pensando en un orden social post-capitalista.

Plantea algunas preguntas de investigación como conclusión que requieren respuesta: 1) ¿se debe rechazar el capitalismo y buscar una 
forma social superior? 2) ¿Es el socialismo esa forma superior? 3) ¿Por qué los fracasos históricos del socialismo? ¿Son inevitables y entonces el socialismo no tiene sentido? 4) ¿Habría que buscar otro sistema alternativo? ¿Cuál?

\section{Síntesis. Economía Social}

¿Se puede hablar de la economía social como un sistema alternativo? Montolio, (2002), afirma que el enfoque económico solidario nace en Europa, probablemente la expresión «economía social» fue empleada por primera vez, por el economista francés Charles Dunoyer (1786-1862) ya en el primer tercio del siglo XIX. Precisamente en 1830 publicó su Nuevo tratado de economía social.

Bastidas, et.al., (2001) y Montolio, (2002), coinciden en que Dunoyer se encuadra, si bien con algún tinte radical, dentro de la escuela francesa del liberalismo económico que encabezara Jean-Baptiste Say (1767-1837) bajo la innegable influencia de la Revolución de 1789.

En Alemania Coraggio J. L., (2012) afirma que, en el siglo XX, Alemania fue protagonista de varios escenarios, uno de ellos las guerras que destruyeron gran parte del país y provocó la división, esto afectó altamente a la economía, ante esta situación, Alemania Federal tuvo que adoptar diversas formas para fortalecer su economía, entre ellas la economía social de mercado, en la cual se ha basado. En la década de 1930, en la universidad alemana de Freiburg, connotados académicos divulgaron una serie de publicaciones que titulaban orden y la Economía, en estas publicaciones se resaltaba que las reglas de esta economía estaban basadas en la libertad individual, sino que también formaban parte de la oposición académica al régimen Nazi. Terminada la segunda guerra mundial, varios de los académicos fueron parte del régimen y fortalecieron la economía social de mercado, esto a finales de 1948, dando paso a una estabilización de la moneda.

Resico, (2008) dice que la economía social de mercado es una teoría completa de la economía y un modo de organización probado de la economía real. Este enfoque se desarrolló en Alemania, y se aplicó a la economía de este país, con un importante éxito luego de la segunda posguerra. Tal es así que los resultados de su aplicación fueron calificados como un «milagro económico» e influyeron notablemente en soluciones similares en países vecinos de la época.

«La Economía Social de Mercado se basa en la organización de mercados como mejor sistema de asignación de recursos, y trata de 
corregir y proveer las condiciones institucionales, éticas y sociales para su operatoria eficiente y equitativa. En los casos requeridos no se abstiene de compensar o corregir posibles excesos o des-balances que puede presentar un sistema económico moderno basado en mercados libres, caracterizada por una minuciosa y extensa división del trabajo, y que, en determinados sectores y bajo ciertas circunstancias, puede alejarse de una competencia leal y eficaz» (Resico, 2008).

La búsqueda científica a decir de Benecke, (2012) por una combinación entre libertad empresarial y responsabilidad social desembocó finalmente en el diseño de una Economía Social de Mercado. Este sistema ha mostrado ser más eficiente en cuanto a la combinación de crecimiento económico y justicia social que los sistemas neo-liberales y socialistas.

Resico, (2008) dice en este sentido la idea de la Economía Social de Mercado propone un marco teórico y de política económico-institucional que busca combinar la libertad de acción individual dentro de un orden de responsabilidad personal y social. Los representantes de esta concepción trabajan en una síntesis consiente de la tradición políticoeconómica liberal en cuanto a los «derechos individuales,» el «republicanismo,» y el «mercado,» con la tradición del pensamiento socialcristiano que enfatiza la «dignidad humana,» la «justicia social» y la «solidaridad».

En este contexto en España a decir de Montolio, (2002), la constitución de la asociación conocida hoy como Centro Internacional de Investigación y de Información de la Economía pública, social y cooperativa (CIRIEC) data de 1947, por otra parte en la Constitución española de 1978 se inscribe dentro de aquel marco europeo en el que la economía social cobra un creciente interés en estos años, atento el constituyente español por lo demás a su entorno. Esta disposición explica el contenido del art. 129.2 del texto constitucional y la declaración de apoyo eficaz a las «diversas formas de participación en la empresa», al cooperativismo y al acceso de los trabajadores a los medios de producción.

\section{Tesis: Capitalismo-Neoliberalismo en América Latina}

Siguiendo la metodología dialéctica es importante partir del capitalismo-neoliberalismo en Latinoamérica que estuvo claramente definida por «El Consenso de Washington (CW)» que a decir de Polo, (2001, pág. 4) constituye el condicionamiento al capital externo como instrumento para la implementación de reformas Neoliberales en América Latina. 


\section{Figura 2. Antecedentes del Consenso de Washington}

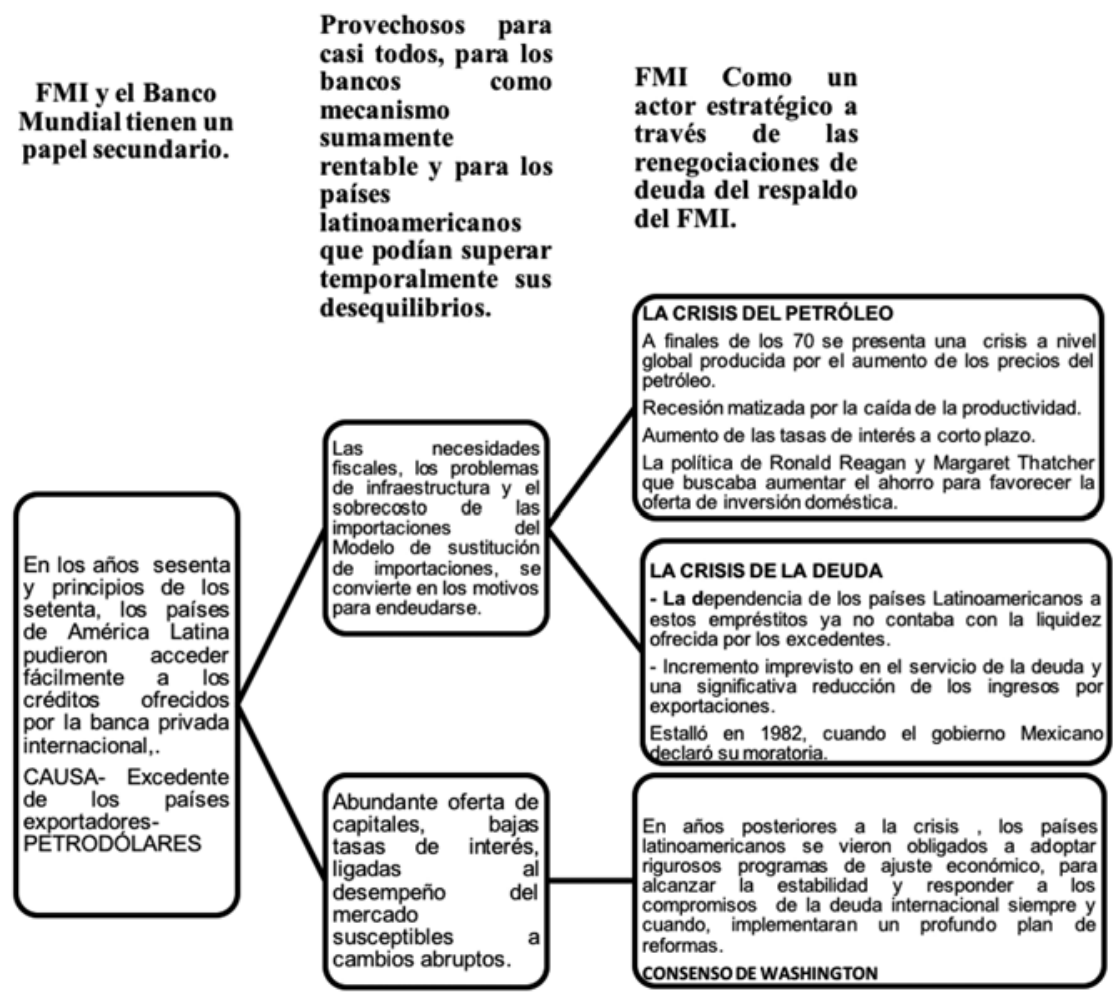

Fuente: Elaboración propia con datos del documento (Polo, 2001, pág. 4)

En Argentina «esta década fue marcada por la finalización de la guerra fría, y el surgimiento del consenso de Washington, paralelamente se realizan las privatizaciones de las Empresas estratégicas del Estado que quedaron en propiedad de empresas transnacionales» (Urbana Gulli, 2015).

Así a decir de Polo, (2001, pág. 14) con el problema de la deuda externa los países acreedores se percataron de la incapacidad de los países deudores de responder a sus compromisos económicos. De esta manera nace el C.W. como la estrategia creada por los países acreedores para afrontar la crisis de la deuda externa y garantizar que los países continuaran pagando el servicio de sus deudas. En adelante, el C.W. debía ser la guía para los gobiernos de países en desarrollo y los organismos internacionales a la hora de valorar los avances en materia económica de los primeros al pedir ayuda a los segundos. 
La agenda del Consenso de Washington como lo afirma Martínez Rangel \& Soto Reyes, (2012) fue diseñada para aliviar los problemas económicos en los que la región se encontraba sumida; sin embargo, de acuerdo a los resolutivos del CW sólo se trataban de recomendaciones por parte de los organismos internacionales y de los denominados think tanks (grupo de expertos). Sus promotores aseguraban que nunca se obligó a un país a implementar este tipo de políticas en sus economías, sin embargo, es importante tomar en cuenta que muchas de aquellas políticas económicas conforman hoy igual que entonces el listado de condiciones que los organismos internacionales exigen para acceder a los préstamos y rescates financieros, por tanto, dichas condiciones responden a los intereses comerciales y financieros de países altamente industrializados.

Por ello Polo, (2001, pág. 36) afirma que el C.W. es el recetario del neoliberalismo por excelencia, de ahí que sus medidas propendan por la reivindicación del poder del mercado y su papel en el desarrollo económico y social, y la prevalencia del sector privado sobre el público, con lo que abogan por la eliminación de la función del Estado en dicho desarrollo. Con este panorama es claro que el paquete de reformas económicas y políticas del CW es una fiel representación del modelo neoliberal: la apertura completa de las economías a los mercados y al capital internacional, el recorte del gasto público y eliminación de los subsidios sociales, la privatización de las empresas estatales y, en general, el establecimiento del clima más propicio para la inversión extranjera. Se enuncian los diez puntos del Consenso de Washington:

Cuadro 1

\section{Los diez puntos del Consenso de Washington}

1) Establecer una disciplina fiscal;

2) Priorizar el gasto público en educación y salud;

3) Llevar a cabo una reforma tributaria;

4) Establecer tasas de interés positivas determinadas por el mercado;

5) Lograr tipos de cambio competitivos;

6) Desarrollar políticas comerciales liberales;

7) Una mayor apertura a la inversión extranjera;

8) Privatizar las empresas públicas;

9) Llevar a cabo una profunda desregulación; y

10) Garantizar la protección de la propiedad privada

Fuente: Elaboración propia con datos de (Martínez Rangel \& Soto Reyes, 2012) 
A continuación se presenta la antítesis del capitalismo en América Latina.

\section{Anti-Tesis. Socialismo-Comunismo en América Latina}

La anti-tesis es el socialismo en América Latina, para Anzuategui Macías, (2016) el término Socialismo del Siglo XXI surgió en 1996, fue acuñado por el sociólogo y analista político, alemán, Heinz Dieterich Steffan. También se le denomina Socialismo Democrático o Socialismo Andino.

A decir de Petit Torres \& Peña Cedillo, (2009) sus características lo hacen radicalmente distinto a las experiencias (y el pensamiento) socialista del siglo pasado, aun cuando es perfectamente reconocible como una evolución de esa corriente histórica, de la cual no reniega, pero al mismo tiempo hace proposiciones muy distintas a las tradicionales, en procura de un socialismo radical y democrático.

El modelo de Estado Socialista del Socialismo del Siglo XXI sigue afirmando Anzuategui Macías, (2016) es un socialismo revolucionario que se inspira en la filosofía y economía marxista y que se sustenta en 4 ejes: el desarrollismo democrático regional, la economía de las equivalencias, la democracia participativa y protagónica; y, las organizaciones de base, sobre la dinámica social y la lucha de clases. En el camino se incorporó un quinto elemento, el Suma Kawsay o Buen Vivir de la población. Se centra mayormente en los gobiernos de los países: Ecuador, Venezuela y Bolivia.

«El «giro a la izquierda» de gran parte de los gobiernos latinoamericanos durante el siglo XXI colocó a las ciencias sociales frente al desafío de analizar las especificidades que asumieron los procesos políticos contemporáneos. La literatura al respecto privilegió, a grandes rasgos, el estudio de dos aspectos transversales a las vigentes experiencias políticas: los contenidos de las agendas post-Consenso de Washington y la recuperación de las capacidades estatales. De este modo, la idea de postneoliberalismo y el Ilamado "retorno del Estado" aparecen como elementos insoslayables de diferentes interpretaciones conceptuales y análisis políticos» (Stoessel, 2014).

Sin embargo, «la continuidad de la derecha en Guatemala, el cambio de sistema de Gobierno en Argentina, el regreso de la derecha al parlamento venezolano y la desestabilización en Brasil, Ecuador, Venezuela y Bolivia permite observar que algo serio está pasando» (Anzuategui Macías, 2016). 
El reto del socialismo es a decir de Petit Torres \& Peña Cedillo, (2009), es justamente, contribuir a la construcción de una fuerza que logre cambiar un sistema que se presenta como muy exitoso, por otro reiteradamente denostado como fracasado, y que debe en sus nuevas versiones tanto rescatar lo positivo que puede rastrearse en su historia, como mostrarse en los hechos capaz de ofrecer beneficios superiores a los que hasta ahora el capital ofrece para todos. Por supuesto, los beneficios del sistema socio-económico alternativo deben estar enmarcados en otra concepción del mundo, darse en un marco de valores muy distintos acerca de la manera en que se debe convivir en sociedad.

La pregunta de investigación es ¿la economía social es esa alternativa?, ¿Es ese punto intermedio entre dos sistemas económicos?

\section{Síntesis. Economía Social en América Latina}

En América Latina a decir de Guerra, (2012) la irrupción del concepto de economía social coincide en el tiempo con el de la economía solidaria y delimita dos orientaciones, una que denomina la clásica en la que los académicos y actores sociales más influidos por la literatura francófona, adoptan la idea de la economía social tal como fue concebida a partir de los años setentas por los europeos y otra de orientación paternalista que surge a finales de los noventa fundamentalmente en el campo de las políticas públicas como una visión más bien minimalista sobre la economía social, esto es, entendiendo por ésta, un conjunto de políticas dirigidas a incluir socialmente a los sectores más vulnerables de la población.

La contribución de una Economía Social consolida en América Latina a decir de Cabra de Luna, (2012) a la gestión del desarrollo que se centra en resolver graves situaciones de pobreza, desigualdad, exclusión, informalidad, explotación humana, falta de cohesión social y deslocalización empresarial y, en fin, generar una distribución más igualitaria de la renta y la riqueza contribuyendo a un cambio necesario de modelo productivo.

"Sin embargo, a lo largo de la década pasada, como resultado de la acción de los principales movimientos sociales (Ecuador, Bolivia), de movilizaciones espontáneas en situaciones de crisis (Argentina, Venezuela) o de la simple reconcentración del electorado popular alrededor de proyectos anunciados como progresistas (Brasil, Uruguay, Paraguay), se fueron sucediendo cambios políticos, reconfirmados electoralmente en todos los casos, como re- 
sultado de los cuales: (a) se desplazó el signo social (ahora más popular) de los gobiernos de turno (b) se aceleró el proceso de implementación de nuevos programas y políticas públicas de sentido popular, (c) en casi todos esos países se formalizó la institucionalización de la Economía Social, mediante nuevos marcos legales, ya sea reconociendo sus formas propias, definiendo nuevas responsabilidades del Estado o modificando los marcos constitucionales, (d) se expandió un sistema de redes virtuales que imprimió mayor velocidad a la mutua influencia de los procesos de cambio, en particular en lo referente a la Economía Social. Se pueden verificar entonces cambios significativos en los formatos institucionales en solo una década. Pero mientras los cambios jurídicos en Argentina y Brasil son ajustes menores al marco preexistente, en Brasil se está iniciado la institucionalización de nuevas prácticas en la co-construcción de política para la Economía Social. Por su parte, en Bolivia y Ecuador se proponen cambios de gran profundidad que requerirán una larga transición, pero tienen la ventaja de estar sustentados en una historia de formas de resistencia o sobrevivencia económica que son hoy reconocidas. Por su parte, en el caso de Venezuela se está proponiendo cambios mayores, pero a partir de tipos ideales construidos que requieren no solo recursos sino un cambio en la cultura de los actores económicos» (Coraggio J. L., 2013).

En Chile, por ejemplo, a decir de Varas, (2014) una gran dificultad en la aplicación de la Economía Social es el bajo conocimiento que existe sobre esta tradición de pensamiento, en particular respecto de sus diferencias con otras corrientes y de sus implicancias concretas»

En Argentina a decir de Coraggio J. L., (2013) con el nuevo gobierno del 2003, ante la constatación de que la crisis del empleo será prolongada, se da una evolución reflexiva de la política social que desemboca en la incorporación, aparentemente para durar, de la política denominada de economía social (reducida a la promoción de emprendimientos mercantiles, aunque de trabajo asociado autogestionado). Se va institucionalizando la «política social de economía social».

En Brasil la principal característica a decir de Coraggio J. L., (2013) es la conformación previa de un movimiento de Ecosol, institucionalizado bajo el título de Foro Brasileño de Economía Solidaria (FBES), que hoy incluye tres actores: los emprendedores económicos solidarios, los promotores de la sociedad civil y los gestores públicos. Es ese movimiento el que, con la asunción en 2003 por Lula da Silva, proveniente del Partido de los Trabajadores (PT), impulsó la creación 
de la SENAES obteniendo la designación de Paul Singer, economista socialista y uno de los fundadores del PT. Simultáneamente se creó el Consejo Nacional de Economía Solidaria (CNES como órgano consultivo y propositivo, con una composición multiactoral similar a la de la FBES). Este grado de institucionalización de la relación estado/sociedad civil ha generado también una correspondiente burocratización del movimiento.

Uno de los grandes problemas continúa diciendo Cabra de Luna, (2012) que lastran el desarrollo de la Economía Social latinoamericana es la dificultad de sistematizar información sobre este sector, lo que consolida su invisibilidad social. Es preciso saber, no solo intuir, el impacto real de la Economía Social.

Es por ello que en el apartado 10 a través de una metodología definida se mide el grado de aceptación de la Economía Social en Europa y América Latina, lo que permite crear grupos homogéneos que visibilizan su situación actual.

\section{Características generales de la Economía Social}

Gaiger describe a la economía social como:

«Aquella que suprime la separación entre los trabajadores y los medios de producción, eliminan la apropiación privada y desaparece el antagonismo entre capital y trabajo, las empresas solidarias ganan la posibilidad de superar el carácter alienante y desechable de la actividad productiva. No estando más ajeno a las determinaciones y al producto de su trabajo, ahora sobre su dominio, el trabajador recupera las condiciones necesarias, sino suficientes, para una existencia integral» (Gaiger, 2001, pág. 206)

En este sentido, para Corrons August, (2016) la economía social y solidaria representa ya una realidad que, si bien todavía dispone de un gran potencial por explotar, aporta un enfoque integrador de la actividad económica, considerando las personas, el medio ambiente y el desarrollo sostenible como referentes prioritarios, por encima de los intereses meramente económicos.

En este contexto Pérez de Mendiguren \& Etxezarreta, (2014) afirma que esta definición integra las tres grandes familias socio-económicas consideradas tradicionalmente como entidades de la Economía Social (cooperativas, mutualidades y asociaciones), dando así carta de naturaleza legal a la existencia de empresas no capitalistas. 


\section{Cuadro 2. Diferencias entre agentes de empresas capitalistas y de economía social}

\begin{tabular}{|c|c|}
\hline Agentes de empresas capitalistas & Agentes de Economía Social \\
\hline $\begin{array}{l}\text { Es un requisito indispensable obtener } \\
\text { beneficios de su actividad productiva. }\end{array}$ & $\begin{array}{l}\text { Pueden obtener beneficios de su ac- } \\
\text { tividad productiva. }\end{array}$ \\
\hline $\begin{array}{l}\text { Necesitan de un capital para desarro- } \\
\text { Ilar su actividad producción, distribu- } \\
\text { ción y comercialización. }\end{array}$ & $\begin{array}{l}\text { Necesitan de un capital para desarro- } \\
\text { Ilar su actividad producción, distribu- } \\
\text { ción y comercialización. }\end{array}$ \\
\hline $\begin{array}{l}\text { Las relaciones existentes entre el ca- } \\
\text { pital y el reparto dependen directa- } \\
\text { mente de la aportación. }\end{array}$ & $\begin{array}{l}\text { Las relaciones existentes entre el ca- } \\
\text { pital y el reparto de los beneficios } \\
\text { son una de las condiciones para la } \\
\text { inclusión de una empresa en la eco- } \\
\text { nomía social. }\end{array}$ \\
\hline $\begin{array}{l}\text { La toma de decisiones está supedita- } \\
\text { da al capital. }\end{array}$ & $\begin{array}{l}\text { La toma de decisiones no debe estar } \\
\text { supeditada al capital, sino a los so- } \\
\text { cios propietarios de la empresa "un } \\
\text { hombre, un voto» }\end{array}$ \\
\hline
\end{tabular}

Fuente: Elaboración propia con datos de (Barea, 1990)

«Lo que va a decidir si una empresa debe ser considerada como dependiente de la economía social es la relación existente entre el capital y la distribución del beneficio de la empresa» (Barea, 1990).

En la Conferencia Europea Permanente de Cooperativas, (2002), órgano representativo de las entidades de economía social europeas, aprobó la Carta de Principios de la Economía Social, documento que recoge los valores fundamentales de la economía social, que hacen diferentes a estas empresas de las empresas capitalistas y de las empresas públicas. Estos principios son:

— Primacía de la persona y del objeto social sobre el capital

- Adhesión voluntaria y abierta

- Control democrático por sus miembros (excepto para las fundaciones que no tienen socios)

- Conjunción de los intereses de los miembros usuarios y del interés general

- Defensa y aplicación de los principios de solidaridad y responsabilidad 
- Autonomía de gestión e independencia respecto de los poderes públicos

- Destino de la mayoría de los excedentes a la consecución de objetivos a favor del desarrollo sostenible, del interés de los servicios a los miembros y del interés general.

\section{Materiales y métodos}

La investigación comienza descomponiendo sus objetos a fin de descubrir el «mecanismo» interno responsable de los fenómenos observados. Pero el desmontaje del mecanismo no se detiene cuando se ha investigado la naturaleza de sus partes; el próximo paso es el examen de la interdependencia de las partes, y la etapa final es la tentativa de reconstruir el todo en términos de sus partes interconectadas.

El método científico puede definirse como «contrastación dialéctica entre la teoría y la práctica» (Ramírez, 1991)

Por ello siguiendo a la dialéctica partiendo de la contrastación entre la teoría y la práctica se realiza un estudio del grado de aceptación de la economía social en Europa y Latinoamérica.

El universo de estudio para el análisis de los indicadores de aceptación del concepto de economía social se toman del estudio "La economía social, en España, Iberoamérica y países del Magreb», donde se recopilan los datos de 17 países de Latinoamérica, a los que se les preguntó por la aceptación del concepto de economía social a autoridades públicas, empresas de economía social y por parte del mundo académico-científico Chaves-Ávila y col., \& Radrigán y col. (2013). Para el caso de los países de la Unión europea los datos del documento «Field of study, quantitative importance and national acceptations» se basan en 27 países Vivet y Thiry, 2000; Monzón y Chaves-Ávila, (2012). Para poder evaluar estadísticamente, se asigna un valor numérico a las respuestas de acuerdo a la información obtenida de las bases de datos, quedando de la siguiente forma: (1) Escaso, (2) Moderado y (3) Elevado (Tablas 1 y 2).

Aunado al análisis cluster que es una técnica estadística multivariante que busca agrupar elementos o (variables) tratando de lograr la mayor homogeneidad en cada grupo y la mayor diferencia entre grupos. Las técnicas de análisis de cluster tienen como objetivo principal la clasificación de un cierto número de individuos Fernández-Santana, (1991). En el presente trabajo, la caracterización significa identificar las principales variables que inciden en el grado de homogeneidad y he- 
terogeneidad existente entre empresas de economía social y empleos ofertados en países de Latinoamérica y Europa, generando grupos representativos de países con economía social. La muestra se basa en el análisis de 17 países de Latinoamérica y 27 de la Unión Europea, divididos en dos grupos; primero, empresas de economía social (cooperativas, mutuas y asociaciones civiles y otros); segundo, empleos (empleos ofertados y empleos de economía social), con un total de cinco variables, información estadística tomada del informe bienio (2008-2009), Observatorio Iberoamericano de Economía Social y Cooperativa (oibescoop) citado en (Chaves-Ávila y Pérez-de-Uralde, 2012; Chaves-Ávila y col., 2013) (Tabla 3).

Se empleó el método de conglomerados jerárquicos, que se puede utilizar para variables cuantitativas y cualitativas, no se conoce el número de conglomerados a priori y cuando el número de objetos no es muy grande el método jerárquico de análisis de cluster (Ward), también conocido como «momento central de orden de dos» o "pérdida de inercia mínima», tiene como principal objetivo optimizar la varianza mínima intragrupal (Ward-Jr., 1963). Se determina la medida de distancia, para este caso, distancia euclídea al cuadrado. En cada paso del proceso de agrupación se trata de combinar aquellos dos conglomerados que provoquen el menor incremento a la suma total de las distancias al cuadrado dentro de los conglomerados.

\section{Resultados}

Aceptación del concepto de Economía Social en países de Latinoamérica

En la Tabla 1 se muestra la aceptación del concepto de Economía Social por países de Latinoamérica por grados: (Escaso) cuando existe un nivel de reconocimiento escaso o nulo de ese concepto en el país; (Moderado) cuando existe un nivel moderado de reconocimiento; y (Elevado) cuando existe un nivel elevado que denota un reconocimiento en el país en cuestión. 


\section{Tabla 1. Aceptación del concepto de Economía Social en Latinoamérica por autoridades públicas, empresas de economía social y mundo académico-científico según el estudio de la Economía Social en Iberoamérica}

\begin{tabular}{rllllllll}
\hline Posición & País & $\begin{array}{c}\text { Por las } \\
\text { Autoridades } \\
\text { Públicas }\end{array}$ & Puntos & $\begin{array}{c}\text { Por las } \\
\text { Empresas } \\
\text { de ES }\end{array}$ & $\begin{array}{c}\text { Por el mundos } \\
\text { Pcadémico- } \\
\text { Científico }\end{array}$ & Puntos & Total \\
\hline 1 & Argentina & Elevado & 3 & Elevado & 3 & Moderado & 2 & 8 \\
2 & Colombia & Elevado & 3 & Elevado & 3 & Moderado & 2 & 8 \\
3 & Honduras & Elevado & 3 & Moderado & 2 & Escaso & 1 & 6 \\
4 & México & Moderado & 2 & Moderado & 2 & Moderado & 2 & 6 \\
5 & Brasil & Escaso & 1 & Escaso & 1 & Moderado & 2 & 4 \\
6 & Costa Rica & Escaso & 1 & Escaso & 1 & Moderado & 2 & 4 \\
7 & Uruguay & Escaso & 1 & Escaso & 1 & Moderado & 2 & 4 \\
8 & Bolivia & Escaso & 1 & Escaso & 1 & Escaso & 1 & 3 \\
9 & Chile & Escaso & 1 & Escaso & 1 & Escaso & 1 & 3 \\
10 & Cuba & Escaso & 1 & Escaso & 1 & Escaso & 1 & 3 \\
11 & Ecuador & Escaso & 1 & Escaso & 1 & Escaso & 1 & 3 \\
12 & El Salvador & Escaso & 1 & Escaso & 1 & Escaso & 1 & 3 \\
13 & Guatemala & Escaso & 1 & Escaso & 1 & Escaso & 1 & 3 \\
14 & Nicaragua & Escaso & 1 & Escaso & 1 & Escaso & 1 & 3 \\
15 & Paraguay & Escaso & 1 & Escaso & 1 & Escaso & 1 & 3 \\
16 & Perú & Escaso & 1 & Escaso & 1 & Escaso & 1 & 3 \\
17 & Venezuela & Escaso & 1 & Escaso & 1 & Escaso & 1 & 3 \\
\hline
\end{tabular}

Fuente: Modificado a partir de datos de (Chaves Ávila, Monzón Campos, Pérez, \& Radrigán Rubio, 2013)

Como se observa en la Tabla 1, Argentina y Colombia se encuentran con una aceptación elevada (8), Honduras y México tienen una aceptación moderada (6), así, como Brasil, Costa Rica y Uruguay (4) y Bolivia, Chile, Cuba, Ecuador, El Salvador, Guatemala, Nicaragua, Paraguay, Perú y Venezuela presentan una aceptación escasa (3) del concepto de Economía Social.

Aceptación del concepto de Economía Social en países de la Unión Europea

En el caso de los países de la Unión Europea, en la Tabla 2 se muestra la aceptación del concepto de Economía Social por países de la Unión Europea por grados: (Escaso) cuando existe un nivel de recono- 
cimiento escaso o nulo de ese concepto en el país; (Moderado) cuando existe un nivel moderado de reconocimiento; y (Elevado) cuando existe un nivel elevado.

\section{Tabla 2. Aceptación del concepto de Economía Social en países de la Unión Europea por autoridades públicas, empresas de economía social y mundo académico-científico según el informe "La Economía Social en la Unión Europea»}

\begin{tabular}{|c|c|c|c|c|c|c|c|c|}
\hline Posición & País & $\begin{array}{c}\text { Por las } \\
\text { Autoridades } \\
\text { Públicas }\end{array}$ & Puntos & $\begin{array}{l}\text { Por las } \\
\text { Empresas } \\
\text { de ES }\end{array}$ & Puntos & $\begin{array}{l}\text { Por el mundo } \\
\text { Académico- } \\
\text { Científico }\end{array}$ & Puntos & Total \\
\hline 1 & España & Elevado & 3 & Elevado & 3 & Elevado & 3 & 9 \\
\hline 2 & Portugal & Elevado & 3 & Elevado & 3 & Moderado & 2 & 8 \\
\hline 3 & Bélgica & Moderado & 2 & Elevado & 3 & Moderado & 2 & 7 \\
\hline 4 & Grecia & Moderado & 2 & Moderado & 2 & Elevado & 3 & 7 \\
\hline 5 & Irlanda & Moderado & 2 & Elevado & 3 & Moderado & 2 & 7 \\
\hline 6 & Francia & Moderado & 2 & Elevado & 3 & Moderado & 2 & 7 \\
\hline 7 & Bulgaria & Moderado & 2 & Moderado & 2 & Moderado & 2 & 6 \\
\hline 8 & Chipre & Moderado & 2 & Moderado & 2 & Moderado & 2 & 6 \\
\hline 9 & Dinamarca & Moderado & 2 & Moderado & 2 & Moderado & 2 & 6 \\
\hline 10 & Finlandia & Moderado & 2 & Moderado & 2 & Moderado & 2 & 6 \\
\hline 11 & Italia & Moderado & 2 & Moderado & 2 & Moderado & 2 & 6 \\
\hline 12 & Luxemburgo & Moderado & 2 & Moderado & 2 & Moderado & 2 & 6 \\
\hline 13 & Polonia & Moderado & 2 & Moderado & 2 & Moderado & 2 & 6 \\
\hline 14 & Alemania & Escaso & 1 & Moderado & 2 & Moderado & 2 & 5 \\
\hline 15 & Austria & Escaso & 1 & Moderado & 2 & Moderado & 2 & 5 \\
\hline 16 & Eslovenia & Escaso & 1 & Moderado & 2 & Moderado & 2 & 5 \\
\hline 17 & Letonia & Escaso & 1 & Moderado & 2 & Moderado & 2 & 5 \\
\hline 18 & Malta & Moderado & 2 & Escaso & 1 & Moderado & 2 & 5 \\
\hline 19 & Reino Unido & Escaso & 1 & Moderado & 2 & Moderado & 2 & 5 \\
\hline 20 & $\begin{array}{l}\text { República } \\
\text { Checa }\end{array}$ & Escaso & 1 & Moderado & 2 & Moderado & 2 & 5 \\
\hline 21 & Suecia & Moderado & 2 & Moderado & 2 & Escaso & 1 & 5 \\
\hline 22 & Estonia & Moderado & 2 & Escaso & 1 & Escaso & 1 & 4 \\
\hline 23 & Hungría & Escaso & 1 & Moderado & 2 & Escaso & 1 & 4 \\
\hline 24 & Lituania & Moderado & 2 & Escaso & 1 & Escaso & 1 & 4 \\
\hline 25 & Eslovaquia & Escaso & 1 & Escaso & 1 & Escaso & 1 & 3 \\
\hline 26 & Países Bajos & Escaso & 1 & Escaso & 1 & Escaso & 1 & 3 \\
\hline 27 & Rumanía & Escaso & 1 & Escaso & 1 & Escaso & 1 & 3 \\
\hline
\end{tabular}

Fuente: Elaboración propia con datos del comité Económico y Social Europeo (2013) 
El grado de aceptación del concepto de Economía Social por país se da respecto al puntaje máximo que puede alcanzar en este análisis de nueve, si la aceptación del concepto de Economía Social por autoridades públicas, empresas de Economía Social y mundo académico-científico es de tres en cada caso.

Como se observa en la Tabla 2, España tiene una aceptación elevada del concepto de Economía Social con tres en cada una de las variables y (9) en total, siendo el único país tanto de la Unión Europea como de los países de Latinoamérica. Portugal con (8) tiene una aceptación elevada, le siguen Bélgica, Francia, Grecia e Irlanda (7). Con una aceptación moderada (6) se observa a Bulgaria, Chipre, Dinamarca, Finlandia, Italia, Luxemburgo y Polonia. Con una aceptación moderada (5) se encuentran Alemania, Austria, Eslovenia, Hungría, Letonia, Malta, Reino Unido, República Checa y Suecia, le siguen (4) Estonia y Lituania. Solo Eslovaquia, Países Bajos y Rumania tienen una aceptación escasa (3) del concepto de Economía Social.

Identificación de grupos homogéneos (Método de Ward)

El análisis clúster es una técnica estadística multivariante que busca agrupar elementos o (variables) tratando de lograr la mayor homogeneidad en cada grupo y la mayor diferencia entre grupos. Las técnicas de análisis de clúster tienen como objetivo principal la clasificación de un cierto número de individuos (Fernández, 1991). En el presente trabajo, la caracterización significa identificar las principales variables que inciden en el grado de homogeneidad y heterogeneidad existente entre empresas de Economía Social y empleos ofertados en países de Latinoamérica y Europa, generando grupos representativos de estos países. La muestra se basa en el análisis de diecisiete países de Latinoamérica y veintisiete de la Unión Europea, con un total de cinco variables divididas en dos grupos; el primero representado por tres tipos de entidades que forman parte de la Economía Social (cooperativas, mutuas y asociaciones civiles y otros) y el segundo, se basa en los empleos (empleos ofertados en el país y empleos de Economía Social), para ello se toma información estadística de (INAES, 2008; Monzón, 2010; Oropeza, 2007; Serva y Andión, 2006; Leite, 2008; FUNDIBES, 2009; Guarín, 1999; Sarmiento, 2010; Díaz, 2008; Da Ros, 2007; CEPES, 2014; Paredes, 2009; COHDESSE, 2003; Rojas, 2006; Pérez y Rádrigan, 2006; Carballo, 2009; FUNDIBES, 2010; De Cárdenas, 2006; Bettoni y Cruz, 1999; Hintze, 2010) citados en (Chaves y Pérez, 2012; Chaves et al., 2013). 
Identificación de grupos homogéneos Latinoamérica

De acuerdo con el Comité Económico y Social Europeo, (2012) la Economía Social en Latinoamérica padece problemas esenciales que dificultan su desarrollo: la falta de visibilidad social e institucional es uno de los más graves. A ello contribuye la ausencia de procesos de medición y cuantificación, lo que impide comprobar sus dimensiones y sus importantes efectos sociales. Invita a una acción más relevante en la elaboración de estadísticas homologadas internacionalmente en los países de Latinoamérica, implicando la colaboración de organismos internacionales como la Comisión Económica para América Latina y el Caribe (CEPAL), Alianza Cooperativa Internacional de las Américas (ACl-Américas), Observatorio Iberoamericano del Empleo y la Economía Social y Cooperativa (OIBESCOOP), o le Centre International de Recherches et d'Information sur l'Economie Publique, Sociale et Coopérative (CIRIEC).

Tabla 3. Actividad de la Economía Social en países de Latinoamérica

\begin{tabular}{llrrrr}
\hline \multicolumn{1}{c}{ País } & Cooperativas & Mutuas & $\begin{array}{c}\text { Asociaciones } \\
\text { Civiles y otros }\end{array}$ & $\begin{array}{c}\text { Total, } \\
\text { Empleos }\end{array}$ & $\begin{array}{c}\text { Empleos de } \\
\text { Economía Social }\end{array}$ \\
\hline 1 Argentina & 12.760 & 4.166 & 74.034 & 16.030 & 289 \\
2 Bolivia & 664 & 9 & 497 & 4.614 & 32 \\
3 Brasil & 7.727 & - & 338.000 & 99.230 & 1.786 \\
4 Chile & 1.152 & 536 & 106.880 & 7.382 & 339 \\
5 Colombia & 8.533 & 273 & - & 20.500 & 150 \\
6 Costa Rica & 530 & - & 4.406 & 1.920 & 101 \\
7 Cuba & 6.398 & - & - & - & - \\
8 Ecuador & 5.422 & - & 2.272 & 4.510 & - \\
9 El Salvador & 3.240 & - & 9 & 2.552 & - \\
10 Guatemala & 841 & - & - & 3.958 & - \\
11 Honduras & 1.048 & - & 84 & 3.237 & - \\
12 México & 13.316 & - & - & 44.710 & 4.864 \\
13 Nicaragua & 3.410 & - & - & 2.262 & - \\
14 Paraguay & 1.371 & 88 & 201 & 3.094 & - \\
15 Perú & 806 & - & - & 10 & - \\
16 Uruguay & 1.164 & 5.000 & 3.566 & 1.631 & 70 \\
17 Venezuela & 61.856 & - & - & 12.370 & - \\
\hline
\end{tabular}

Fuente: Modificado a partir de datos de (Chaves Ávila \& Pérez de Uralde, 2012) 
Uno de los grandes problemas que lastran el desarrollo de la Economía Social en Latinoamérica es la dificultad de sistematizar información sobre este sector, lo que consolida su invisibilidad social. Es preciso saber, no solo intuir, el impacto real de la Economía Social. La ausencia de mediciones hace muy difícil destacar su verdadera relevancia social y la diferencia comparativa con respecto a otros tipos de empresas en cuanto al impacto de sus acciones económicas, sociales y solidarias. Lo mismo se pide en Europa para este sector, reconocimiento estadístico, para cada sector y rama de actividad, para conseguir más visibilidad.

El análisis refleja que el número de cooperativas en Latinoamérica oscila entre 530 de Costa Rica y 61.856 de Venezuela, que proporciona una media de 7.661,06 cooperativas en países de Latinoamérica. En los países latinoamericanos se tiene una media de 448,88 empleos de Economía Social, de una oferta laboral de 228.010 puestos. El número de asociaciones civiles y otros organismos de Economía Social es muy superior al de cooperativas y mutuas. En este sentido, las cooperativas representan el 19,43\% y las mutuas el 1,50\%.

El hecho de considerar valores absolutos (total de cooperativas, de mutuas, de asociaciones civiles y otros, total de empleos ofertados y empleos de Economía Social) en lugar de los números promedio del Producto Interno Bruto (PIB) por ejemplo, genera que los países con mayor riqueza económica tengan una mayor infraestructura, más empresas de Economía Social y consigan mayores ofertas de empleo. Este hecho genera casos atípicos de las variables analizadas.

El total de empleos presenta dos casos atípicos identificados con los números 12 (México) y 3 (Brasil), que son los dos países con mayor oferta de empleos. Coinciden, también los dos casos atípicos que se presentan en el número de empleos de Economía Social 12 (México) y 3 (Brasil).

Respecto a las empresas de Economía Social, se reflejan casos atípicos en los casos 1 (Argentina), 3 (Brasil), 4 (Chile), 5 (Colombia), 16 (Uruguay) y 17 (Venezuela).

La localización de los casos atípicos indica que se trata de distribuciones con asimetría positiva. Distribuciones que es necesario simetrizar antes de aplicar el análisis de clúster. Considerando la escalera de las transformaciones de Tukey, la asimetría positiva se corrige sustituyendo los datos recogidos por su raíz cuadrada o su logaritmo; en el caso de que las transformaciones proporcionen resultados muy similares se opta por la menos potente (Mora y Rodríguez, 2001). En este caso, se opta por realizar una transformación raíz cuadrada a las variables con valores atípicos. 
Se observa una relación de la variable Total_empleosR con Empleos_ESR y Asociaciones Civiles y OtrosR del modelo, relaciones significativas al $0.01(* *)$, por lo que se procede a eliminarla del modelo.

Un análisis detallado de los coeficientes revela una gran similitud en la actividad de la Economía Social en Guatemala y Perú (con una distancia de 0,000). Otras Comunidades con pautas parecidas son Nicaragua y El Salvador (con una distancia de 0,001), Honduras y Guatemala (con una distancia de 0,007) y Honduras y Perú (con 0,008). Los países más diferentes en cuanto a la actividad de Economía Social son Venezuela y Brasil (con una distancia de 26,4).

\section{Figura 3. Dendograma que utiliza una vinculación de Ward Combinación de conglomerados de distancia re-escalados Países de Latinoamérica}

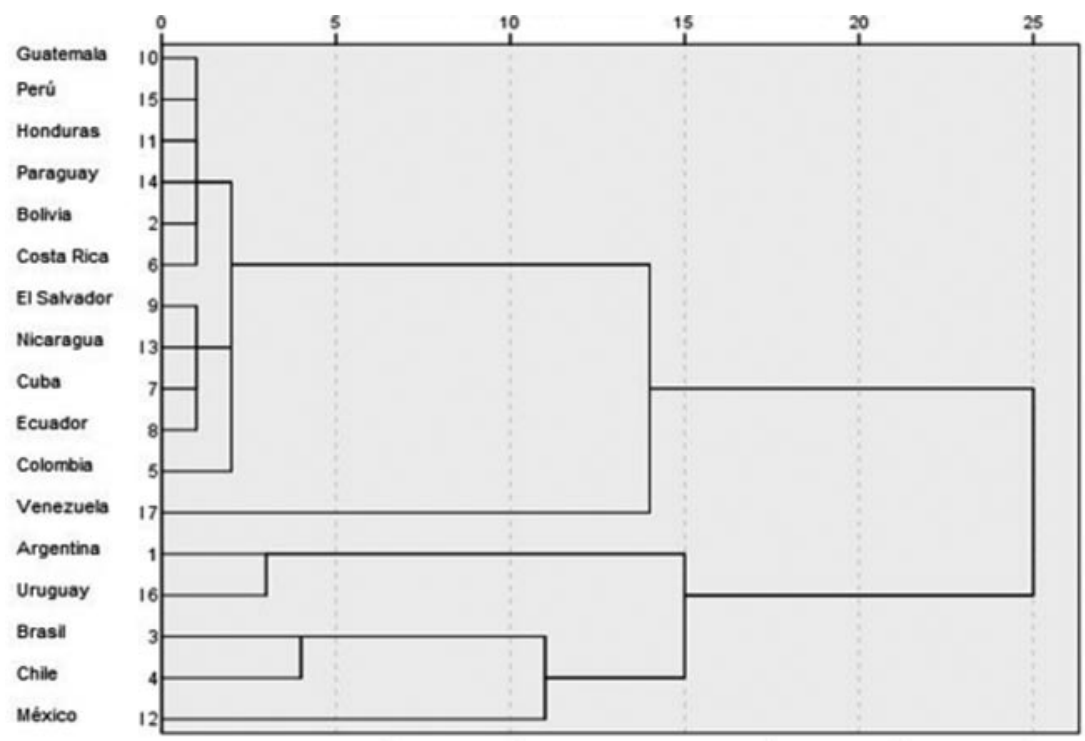

Fuente: Elaboración propia corresponde a los países de Latinoamérica

La lectura del dendograma de la vinculación de Ward se realiza de izquierda a derecha, y en su interior aparecen líneas horizontales y verticales, utilizando estas últimas para indicar el punto de unión entre dos países. Así la posición de la línea vertical respecto a la regla situada en la parte superior indica la distancia donde se ha realizado la unión de dos grupos, de modo que cuanto más a la derecha se produzca una agrupación existirá más diferencia entre los casos, formando grupos más hete- 
rogéneos. En la regla de la parte superior muestra la distancia entre los agrupamientos, si bien se ha cambiado la «escala» de las distancias a unos valores que oscilan entre 0 y 25 , mientras que la amplitud de las distancias del historial de conglomeración oscila entre 0,00 y 64 . Es decir, la amplitud de las distancias $(0,00-64)$ se calcula para adoptarla a la escala (0-25), basta con multiplicar cada amplitud por 0,390625. Respecto a la nueva escala, en la distancia $2,09(5,348)$ se produce el primer gran incremento en las distancias para unirse Guatemala, Perú, Honduras, Paraguay, Bolivia, Costa Rica con El Salvador, Nicaragua, Cuba, Ecuador y Colombia. En la distancia 3,28 $(8,409)$ se unen Argentina y Uruguay. En la distancia 6,82 $(17,469)$ se unen Brasil, Chile y México.

\section{Tabla 4. Análisis descriptivo de los resultados Países de Latinoamérica}

\begin{tabular}{|c|c|c|c|c|c|}
\hline & Método Ward & Empleos ES & Cooperativas & Mutuas & $\begin{array}{l}\text { Asociaciones } \\
\text { Civiles y otros }\end{array}$ \\
\hline 1 & $\begin{array}{l}\text { Media } \\
\text { N } \\
\text { Desviación típica } \\
\text { Mínimo } \\
\text { Máximo } \\
\text { \% de la suma total }\end{array}$ & $\begin{array}{r}179,50 \\
2 \\
154.856 \\
70 \\
289 \\
4,7 \%\end{array}$ & $\begin{array}{r}6.962,00 \\
2 \\
8.199 .610 \\
1.164 \\
12.760 \\
10,7 \%\end{array}$ & $\begin{array}{r}4.583,00 \\
2 \\
589.727 \\
4.166 \\
5.000 \\
91,0 \%\end{array}$ & $\begin{array}{r}38.800,00 \\
2 \\
49.828 .401 \\
3.566 \\
74.034 \\
14,6 \%\end{array}$ \\
\hline 2 & $\begin{array}{l}\text { Media } \\
\text { N } \\
\text { Desviación típica } \\
\text { Mínimo } \\
\text { Máximo } \\
\text { \% de la suma total }\end{array}$ & $\begin{array}{r}23,58 \\
12 \\
49.590 \\
0 \\
150 \\
3,7 \%\end{array}$ & $\begin{array}{r}7.843,25 \\
12 \\
17.210 .707 \\
530 \\
61.856 \\
72,3 \%\end{array}$ & $\begin{array}{r}30,83 \\
12 \\
80.309 \\
0 \\
273 \\
3,7 \% \\
\end{array}$ & $\begin{array}{r}622,42 \\
12 \\
1.355 .814 \\
0 \\
4.406 \\
1,4 \%\end{array}$ \\
\hline 3 & $\begin{array}{l}\text { Media } \\
\text { N } \\
\text { Desviación típica } \\
\text { Mínimo } \\
\text { Máximo } \\
\text { \% de la suma total }\end{array}$ & $\begin{array}{r}2.329,67 \\
3 \\
2.310 .971 \\
339 \\
4.864 \\
91,6 \% \\
\end{array}$ & $\begin{array}{r}7.398,33 \\
3 \\
6.088 .657 \\
1.152 \\
13.316 \\
17,0 \%\end{array}$ & $\begin{array}{r}178,67 \\
3 \\
309.460 \\
0 \\
536 \\
5,3 \%\end{array}$ & $\begin{array}{r}148.293,33 \\
3 \\
172.763 .706 \\
0 \\
338.000 \\
83,9 \%\end{array}$ \\
\hline Total & $\begin{array}{l}\text { Media } \\
\text { N } \\
\text { Desviación típica } \\
\text { Mínimo } \\
\text { Máximo } \\
\text { \% de la suma total }\end{array}$ & $\begin{array}{r}448,88 \\
17 \\
1.216 .037 \\
0 \\
4.864 \\
100,0 \%\end{array}$ & $\begin{array}{r}7.661,06 \\
17 \\
14.580 .065 \\
530 \\
61.856 \\
100,0 \%\end{array}$ & $\begin{array}{r}592,47 \\
17 \\
1.515 .706 \\
0 \\
5.000 \\
100,0 \%\end{array}$ & $\begin{array}{r}31173.47 \\
17 \\
84655775 \\
0 \\
338000 \\
100.0 \%\end{array}$ \\
\hline
\end{tabular}

Fuente: Elaboración propia grupo de conglomerados 
El conglomerado número uno destaca por ser el que más mutuas tiene con el $91 \%$. El conglomerado número dos es el que más cooperativas tiene con $72,3 \%$, pero también tiene el menor porcentaje de empleos de Economía Social con 3,7\%, mutuas 3,7\% y asociaciones civiles y otros organismos de Economía Social con 1,4\%. El conglomerado número tres destaca por tener más empleos de Economía Social con $91,6 \%$, y más asociaciones civiles y otros organismos de Economía Social con $83,9 \%$.

\section{Identificación de grupos homogéneos Unión Europea}

El análisis de estadísticos descriptivos refleja que el número de cooperativas oscila entre 250 en Malta y 1.128.381 cooperativas en Italia, que proporciona una media de 168.459,04 cooperativas en los países de la Unión Europea analizados. En los países se tiene una media de 14.128,13 empleos de Economía Social, de una oferta laboral de $216.397,80$ puestos.

El número medio de asociaciones civiles y otros organismos de Economía Social es muy superior al de cooperativas y mutuas; en este sentido, las cooperativas representan el 49,35 \% y las mutuas el 3,93\%.

Las variables empleos ofertados y empleos de Economía Social presentan cuatro casos atípicos identificados con los números 2 (Alemania), 8 (Reino Unido), 10 (Francia) y 14 (Italia), que son los cuatro países con mayor oferta de empleos. Coinciden también con los cuatro casos atípicos que se presentan en el número de empleos de Economía Social.

Se observó una correlación entre las variables del modelo, relaciones significativas al 0,01, por lo que se determina una medida (distancia de Mahalanobis) para compensar la correlación, ya que si las variables se encuentran correlacionadas se corre el peligro de incluir información redundante que se debe evitar en todo momento.

Se cumple con la revisión del criterio de valor atípico multivariante extremo, donde son aquellos cuya probabilidad sea menor a 0.001, en la muestra ninguno es atípico y se procede al análisis clúster.

El análisis detallado de los coeficientes revela una gran similitud en la actividad de la Economía Social en Hungría y República Checa (con una distancia de 0,071), Malta y Chipre (con una distancia de 0,071). Otras Comunidades con pautas parecidas son Hungría y Finlandia (con una distancia de 0,073), Luxemburgo y Malta (con una distancia de 0,088), y Chipre con Letonia (a una distancia de 0,092). Los países más diferentes en cuanto a la actividad de Economía Social son Alemania 
con Malta (con una distancia de 53,981) y Alemania con Letonia (con una distancia de 52,285).

Tabla 5. Actividad de la Economía Social en países de la Unión Europea

\begin{tabular}{|c|c|c|c|c|c|c|c|}
\hline & País & Cooperativas & Mutuas & Asociaciones & Total & $\begin{array}{c}\text { Total } \\
\text { empleos }\end{array}$ & $\begin{array}{c}\text { Empleos } \\
\text { ES }\end{array}$ \\
\hline 1 & Bélgica & 13,547 & 11,974 & 437,020 & 462,541 & $4,488.70$ & 462.54 \\
\hline 2 & Alemania & 830,258 & 86,497 & $1,541,829$ & $2,458,584$ & $38,737.80$ & $2,458.58$ \\
\hline 3 & Irlanda & 43,328 & 650 & 54,757 & 98,735 & $1,847.80$ & 98.74 \\
\hline 4 & Grecia & 14,983 & 1,140 & 101,000 & 117,123 & $4,388.60$ & 117.12 \\
\hline 5 & Luxemburgo & 1,933 & - & 14,181 & 16,114 & 220.80 & 16.11 \\
\hline 6 & Países Bajos & 184,053 & 2,860 & 669,121 & 856,034 & $8,370.20$ & 856.05 \\
\hline 7 & Austria & 61,999 & 1,416 & 170,113 & 233,528 & $4,096.30$ & 233.53 \\
\hline 8 & Reino Unido & 236,000 & 50,000 & $1,347,000$ & $1,633,000$ & $28,941.50$ & $1,633.00$ \\
\hline 9 & España & 646,397 & 8,700 & 588,056 & $1,243,153$ & $18,456.50$ & $1,243.15$ \\
\hline 10 & Francia & 320,822 & 128,710 & $1,869,012$ & $2,318,544$ & $25,692.30$ & $2,318.54$ \\
\hline 11 & Portugal & 51,391 & 5,500 & 194,207 & 251,098 & $4,978.20$ & 251.10 \\
\hline 12 & Finlandia & 94,100 & 8,500 & 84,600 & 187,200 & $2,447.50$ & 187.20 \\
\hline 13 & Dinamarca & 70,757 & 4,072 & 120,657 & 195,486 & $2,706.10$ & 195.49 \\
\hline 14 & Italia & $1,128,381$ & - & $1,099,629$ & $2,228,010$ & $22,872.30$ & $2,228.01$ \\
\hline 15 & Suecia & 176,816 & 15,825 & 314,568 & 507,209 & $4,545.80$ & 507.21 \\
\hline 16 & $\begin{array}{l}\text { República } \\
\text { Checa }\end{array}$ & 58,178 & 9 & 9 & 160 & $4,885.20$ & 09 \\
\hline 17 & Estonia & 9,850 & - & 28,000 & 37,850 & 570.90 & 37.85 \\
\hline 18 & Chipre & 5,067 & - & - & 5,067 & 385.10 & 5.07 \\
\hline 19 & Letonia & 440 & - & - & 440 & 940.90 & 0.44 \\
\hline 20 & Lituania & 8,971 & - & - & 8,971 & $1,343.70$ & 8.97 \\
\hline 21 & Hungría & 85,682 & 6,676 & 85,852 & 178,210 & $3,781.20$ & 178.21 \\
\hline 22 & Malta & 250 & - & 1,427 & 1,677 & 164.20 & 1.68 \\
\hline 23 & Polonia & 400,000 & 2,800 & 190,000 & 592,800 & $15,960.50$ & 592.80 \\
\hline 24 & Eslovenia & 3,428 & 476 & 3,190 & 7,094 & 966.00 & 7.09 \\
\hline 25 & Eslovaquia & 26,090 & 2,158 & 16,658 & 44,906 & $2,317.50$ & 44.91 \\
\hline 26 & Bulgaria & 41,300 & - & 80,000 & 121,300 & $3,052.80$ & 121.30 \\
\hline 27 & Rumanía & 34,373 & 18,999 & 109,982 & 163,354 & $9,239.40$ & 163.35 \\
\hline
\end{tabular}

Total

4,548,394.00 362,632.00 9,217,088.00 14,128,114.00 216,397.80 14,128.13

Fuente: Elaboración propia con datos de (Vivet y Thiry, 2000; Monzón y Chaves-Ávila, 2012). 
Se observó que República Checa (16) y Hungría (21) son las primeras Comunidades que se unen en el Historial de Aglomeración. De la última columna (Próxima etapa), se desprende que este primer agrupamiento volverá a ser utilizado en la etapa 9.

La amplitud de las distancias del historial de conglomeración oscila entre 0,036 y 130. Es decir, la amplitud de las distancias (0,036-130) se calcula para adoptarla a la escala (0-25), basta con multiplicar cada amplitud por 0,19230769. Respecto a la nueva escala, en la distancia 2,45 $(12,764)$ se produce el primer gran incremento en las distancias para unirse (23) Polonia, (6) Países Bajos, (14) Italia, (9) España. En la distancia 5,58 $(29,011)$ se unen (2) Alemania, (10) Francia y (8) Reino Unido. En la distancia 8,99 $(46,756)$ se unen (1) Bélgica, (3) Irlanda, (4) Grecia, (5) Luxemburgo, (7) Austria, (11) Portugal, (12) Finlandia, (13) Dinamarca, (15) Suecia, (16) Rep. Checa, (17) Estonia, (18) Chipre, (19) Letonia, (20) Lituania, (21) Hungría, (22) Malta, (24) Eslovenia, (25) Eslovaquia, (26) Bulgaria, (27) Rumania (Gráfico 8).

\section{Figura 4. Dendograma que utiliza una vinculación de Ward Combinación de conglomerados de distancia re-escalados Países de la Unión Europea}

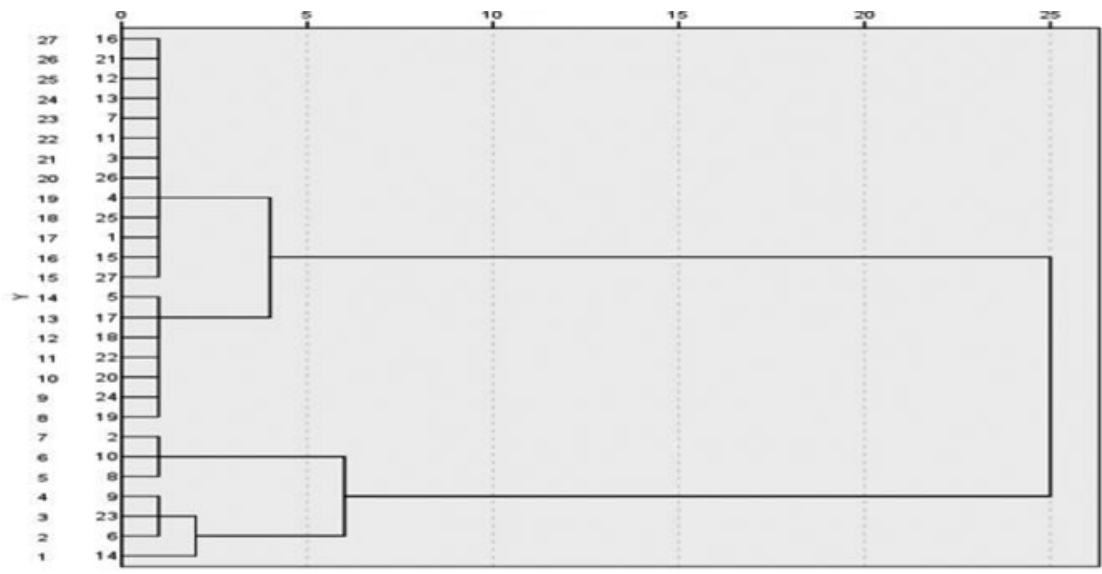

Fuente: Elaboración propia corresponde a los países de la Unión Europea 
Tabla 6. Clasificación de conglomerados

\begin{tabular}{lrrrrr}
\hline Método Ward & Cooperativas & Mutuas & Asociaciones & Total, empleos & Empleos ES \\
\hline Media & $40.124,15$ & $4.153,25$ & $95.622,05$ & $2.868,335$ & 139,9 \\
N & 20 & 20 & 20 & 20 & 20 \\
Desviación típica & $43.655,009$ & $5.686,047$ & $113.563,986$ & $2.250,24969$ & 144,50139 \\
Mínimo & 250 & 0 & 0 & 164,2 & 0,44 \\
Máximo & 176.816 & 18.999 & 437.020 & $9.239,4$ & 507,21 \\
\% de la suma total & $17,60 \%$ & $22,90 \%$ & $20,70 \%$ & $26,50 \%$ & $19,80 \%$ \\
\hline Media & 462.360 & $88.402,33$ & 1.585 .947 & $31.123,8667$ & $2.136,7067$ \\
N & 3 & 3 & 3 & 3 & 3 \\
Desviación típica & $321.419,347$ & $39.389,58$ & $263.787,662$ & $6.791,04637$ & 441,80664 \\
Mínimo & 236.000 & 50.000 & 1.347 .000 & $25.692,3$ & 1.633 \\
Máximo & 830.258 & 128.710 & 1.869 .012 & $38.737,8$ & $2.458,58$ \\
\% de la suma total & $30,50 \%$ & $73,10 \%$ & $51,60 \%$ & $43,10 \%$ & $45,40 \%$ \\
\hline Media & $589.707,75$ & 3.590 & $636.701,5$ & $16.414,875$ & $1.230,0025$ \\
N & 4 & 4 & 4 & 4 & 4 \\
Desviación típica & $405.761,567$ & $3.658,652$ & $372.943,923$ & $6.077,00098$ & $716.95,172$ \\
Mínimo & 184.053 & 0 & 190.000 & $8.370,2$ & 592,8 \\
Máximo & 1.128 .381 & 8.700 & 1.099 .629 & $22.872,3$ & $2.228,01$ \\
\% de la suma total & $51,90 \%$ & $4,00 \%$ & $27,60 \%$ & $30,30 \%$ & $34,80 \%$ \\
\hline Media & $168.459,04$ & $13.430,81$ & $341.373,63$ & $8.014,7333$ & 523,2641 \\
N & 27 & 27 & 27 & 27 & 27 \\
Desviación típica & $279.772,551$ & $29.566,45$ & $519.063,794$ & $10.215,54106$ & 761,47746 \\
Mínimo & 250 & 0 & 0 & 164,2 & 0,44 \\
Máximo & 1.128 .381 & 128.710 & 1.869 .012 & $38.737,8$ & $2.458,58$ \\
\% de la suma total & $100,00 \%$ & $100,00 \%$ & $100,00 \%$ & $100,00 \%$ & $100,00 \%$ \\
\hline Tota $\%$ & & & \\
\hline
\end{tabular}

Fuente: Elaboración propia grupo de conglomerados

El conglomerado número uno destaca por ser el que más empleos ofrece con el $26,50 \%$. El conglomerado número dos es el que más mutuas tiene $73,10 \%$ así como asociaciones civiles y otros organismos de Economía Social $51,60 \%$. El conglomerado número tres por tener más cooperativas $51,90 \%$ y menor cantidad de mutuas $4,00 \%$.

\section{Conclusión}

La contrastación dialéctica permite observar los efectos económicos y sociales de los sistemas económicos y la dificultad de una postura argumentativa radical; la tesis capitalista, la anti-tesis socialista y la posibilidad de una síntesis propuesta como la economía social es difícil, toda vez que, el capitalismo ha originado profundas desigualdades y un po- 
der desproporcionado a la gran empresa y trasnacional aunque su base argumentativa sea el bien común, sin embargo, el socialismo cuando no esta en poder de la clase trabajadora parece encontrarse al extremo opuesto y genera también serias desigualdades, la síntesis es una tarea realmente complicada, sin embargo, a pesar de surgir a mediados del siglo pasado, el concepto de Economía Social en la actualidad, se enfrenta a nuevos retos para seguir creciendo y fortaleciéndose como agente político, social y económico. Está vigente como una posible solución contra la desigualdad y propone prácticas alternativas al sistema económico actual de algunos países mediante la aplicación de valores universales, como la equidad, la justicia, la fraternidad económica, la solidaridad social, el compromiso con el entorno y la democracia directa.

La aceptación del concepto de Economía Social en Latinoamérica es escasa en las tres variables, por lo que se puede indicar que ni las autoridades públicas, ni las empresas de Economía Social y ni el mundo académico-científico mantienen una posición clara respecto a la definición de Economía Social. En Europa, la aceptación del concepto de Economía Social es moderada y alta, aceptándola más la comunidad académico-científica y las empresas de Economía Social.

El método de Ward trata de ir agrupando de forma jerárquica elementos de modo que se minimice una determinada función objetivo. Persigue la minimización de la variación intra-grupal de la estructura formada. Tiende a generar conglomerados demasiado pequeños y demasiado equilibrados en tamaño, no calcula distancias, maximiza la homogeneidad dentro de grupos, plantea todas las posibilidades en cada etapa. Se logra la caracterización de las principales variables que inciden en el grado de homogeneidad y heterogeneidad existente entre empresas de Economía Social y empleos ofertados, generando grupos representativos de países con Economía Social en Latinoamérica y Europa. Se puede comparar el resultado de los conglomerados (análisis de Ward) con el grado de aceptación del concepto de Economía Social y demostrar si coincide con el grado de aceptación por parte de empresas de Economía Social, ya que se utilizan las variables: empresas de Economía Social y empleos ofertados.

\section{Fuentes documentales}

Anónimo. (SF). México desconocido. Obtenido de https://www.mexicodesconocido.com.mx/el-mayordomo-una-tradicion-colonial-aun-vigente.html ANZUATEGUI MACÍAS, D. 2016. ¿Crisis o fin del Socialismo en América Latina? Revista de Ciencias Sociales y Humanidades (1), 6. 
BAREA, J. 1990. Concepto y Agentes de la Economía Social. CIRIEC-España. Revista de Economía Pública, Social y Cooperativa (8), 109-117.

BASTIDAS, Delgado Oscar, Richer Medelaine. 2001. Economía social y economía solidaria: Intento de definición . Cayapa. Revista Venezolana de Economía Social (1), 2.

BELTRÁN, E. (SF). Obtenido de http://www.grupomesofilo.org/pdf/proyectos/ DE/DE_chinantecos.pdf

BENECKE, D. W. 2012. Un sistema socioeconómico entre Neo-Liberalismo y Socialismo. Quito-Ecuador: Konrad Adenauer Stiftung.

BETTELHEIM, C. 1979. Las luchas de clases en la URSS. Segundo período, 1923-1929. México: Siglo XXI.

BETTONI, A. y A. Cruz. 1999. El tercer sector en Uruguay, Ed. Instituto de Comunicación y Desarrollo, Montevideo, Uruguay, p. 15.

BOAVENTURA, D. S. 2009. Sociología jurídica crítica Para un nuevo sentido común en el derecho. Bogota: Trotta.

BOBBIO, N. 1991. El futuro de la democracia. México: Fondo de Cultura Económica.

BUNGE, M. 2010. ¿Existio el socialismo alguna vez, y tiene porvenir? . Lecciones y Ensayos (88), 17.

CABRA DE LUNA, M. 2012. Economía Social en America Latina. Bruselas : Comité Económico y Social Europeo .

CARBALLO, U. 2009. La legislación cooperativa en Nicaragua. Alianza Cooperativa internacional para las Américas, San José Costa Rica. Disponible en línea: http:// http://www.aciamericas.coop/Situacion-y-diagnostico-de-la [última consulta, marzo 2017].

CHAVES ÁVILA, R., Monzón Campos, J. L., Pérez, J. M., \& Radrigán Rubio, M. 2013. La economía social en clave internacional. cuantificación, reconocimiento institucional y visibilidad social en europa, iberoamérica y norte de áfrica. REVESCO. Revista de Estudios Cooperativos, Num. 112, p. 122-150.

COHDESSE. 2003. Consejo Hondureño del Sector Social de la Economía. La economía Social en Honduras. Documento ilustrativo preparado para la membresía del sector, el $\mathrm{GOH}$ y otras entidades nacionales e internacionales. p. 20, Honduras.

Comité Económico y Social Europeo. 2012. La economía social en América Latina. Bruselas: Miguel Ángel Cabra de Luna, pp.1-12.

Confederación Empresarial Española de la Economía Social CEPES. 2014. Empresas relevantes de la economía social :20132014. Madrid: Cepes.

Conferencia Europea Permanente de Cooperativas, M. A. 2002. Conferencia Europea Permanente de Cooperativas, Mutualidades, Asociaciones y Fundaciones (CEP-CMAF). Es: Conferencia Europea.

CORAGGIO, J. L. 2013. La Presencia de la Economía Social y Solidaria (ESS) y su Institucionalización en América Latina. Potential and Limits of Social and Solidarity Economy (pág. 3). Geneva, Switzerland : Red Latinoamericana de Investigadores en Economía Social y Solidaria (RILESS).

CORAGGIO, J. L. 2012. Conocimiento y Políticas Públicas de Economía Social y Solidaria, Problemas y Propuestas. IAEN . 
CORRONS AUGUST, G. M. 2016. La economía social: experiencias y retos. Revista de economía, empresa y sociedad (6), 8.

CRUZ, S. L. 2002. Neoliberalismo y globalización económica. Revista Contaduría y Administración (205), 20.

DA ROS, G. 2007. El movimiento cooperativo en el Ecuador. Visión histórica, situación actual y perspectivas, CIRIEC - España, Revista de Economía Pública, Social y Cooperativa 057, abril, Centro Internacional de Investigación e Información Sobre la Economía Pública, Social y Cooperativa, Valencia, España, pp. 249-284.

DE CÁRDENAS, L. G. 2006. La economía social en Perú, en Fundación Iberoamericana de Economía Social-FUNDIBES: La Economía Social Iberoamericana. Un acercamiento a su realidad, vol. 2, FUNDIBES, España.

DÍAZ, B. 2008. El sector de la Economía Social en Cuba: importancia económica y social, en Fundación Iberoamericana de la Economía Social - FUNDIBES: La Economía Social en Iberoamérica. Realidad y proyecciones, una visión comparada, vol. 3, FUNDIBES, España.

ENGELS, F. 1980. Carta de Engels a José Block . Londres: Progreso Moscú.

FERNÁNDEZ SANTANA, O. 1991. El análisis de cluster: Aplicación, interpretación y validación. Papers: Revista De Sociologia, (37), 065-76.

Foro Economico Mundial. (10 de 2015 de 2015). Informe de riesgos globales 2012. Obtenido de Foro Económico: http://reports.weforum.org/globalrisks-2012/?doing_wp_cron=1478086016.0533339977264404296875

FUNDIBES. 2009. Anuario Iberoamericano de la Economía Social. Ed. Fundación Iberoamericana de Economía Social, Madrid, p.364.

FUNDIBES. 2010). Anuario Iberoamericano de la Economía Social. Ed. Fundación Iberoamericana de Economía Social, Madrid, p.331.

GAIGER, L. (2001. Virtudes do trabalho nos empreendimentos económicos solidários. Revista Latinoamericana de Estudios del Trabajo, Asociación Latinoamericana de Sociología del Trabajo (13).

GONZALES, A. 2014. Historia Universal. Obtenido de http://www.historiacultural.com/2014/10/pueblo-cultura-mixe.html

GUARÍN, B. 1999. Situación y diagnóstico de la legislación cooperativa en Colombia. Situación actual de las leyes en América Latina, Alianza Cooperativa internacional para las Américas, San José Costa Rica. Disponible en línea: http:// http://www.aciamericas.coop/Situacion-y-diagnostico-de-la [última consulta, marzo 2017].

GUERRA, P. 2012. Investigación sobre Políticas de empleo, de trabajo y de integración social. Análisis del caso nacional en una perspectiva regional comparada. Uruguay: Universidad de la República Facultad de Derecho Carrera de Relaciones Laborales .

GUTENBERG, M. O. 2010. Economía Social de Mercado. Una respuesta humanista que supera disyuntiva de Estado o Mercado. Santiago, Chile: JC Sáez Editor SpA.

HURTADO, L. O. 2010. Neoliberalismo y Economía Social de Mercado. Chile: JC Sáez Editor SpA. 
INAES 2008. Las Cooperativas y las Mutuales en la República Argentina. Reempadronamiento Nacional y Censo Económico Sectorial de las Cooperativas y Mutuales, Ed. Instituto Nacional de Asociativismo y Economía Social, Buenos Aires, Argentina, p. 107.

IZQUIERDO, M.E. 2017. «La adhesión voluntaria e identidad cooperativa en las empresas cooperativas mexicanas». Boletín de la Asociación Internacional de Derecho Cooperativo, núm. 51, 21-44.

MARQUES, G. 2015. Las Asignaturas Pendientes del Liberalismo Económico. Revista Mad, 9.

MARTínEZ HEREDIA, F. 2008. El socialismo. Cuadernos de Pensamiento Crítico (1), 13-39.

MARTíNEZ RANGEL, R., \& Soto Reyes, E. 2012. El Consenso de Washington: la instauración de las políticas neoliberales en América Latina. Política y Cultura (37), 10.

MATIAS, G. A., \& Hernández, A. A. 2014. Positivismo, Dialéctica Materialista y Fenomenología: Tres Enfoques Filosóficos del Método Científico y la Investigación Educativa. Actualidades Investigativas en Educación, 10.

MONTOLIO, J. 2002. Economía social: concepto, contenido y significación en España. CIRIEC-España, Revista de Economía Pública, Social y Cooperativa (42), 5-31.

MORA-CATALÁ, R. y Rodríguez-Jaume, M. J. 2001. Anexo 2. Etiquetado, recodificación y transformación de variables. Técnicas de Investigación Social II. https://rua.ua.es/dspace/bitstream/10045/12878/1/A2-ETIQUETA-RECODETRNASFORMA.pdf. Fecha de consulta: 15 de febrero de 2016.

MUÑOZ, C. A. 2015. Socialismo o comunismo diferencias entre John Stuart Mill y Karl Marx. Inciso, 2 (17), 1.

OLIVERA, F. G. 2003. INFORME FINAL DE RESULTADOS DE LA MUESTRA REPRESENTATIVA EN CAMPO EN EL ESTADO DE OAXACA . Oaxaca: Centro de Investigaciones y Estudios Superiores en Antropología Social .

OROPEZA, F. 2007. Estados asociados. República de Bolivia, en Confederación Empresarial Española de la Economía Social - CEPES, ACI Américas y centro Cooperativo Sueco: Políticas Publicas en materia de cooperativas. MERCOSUR, Intercoop Editora Cooperativa Limitada, buenos Aires, Argentina.

PALLEY, T. 2014. Economía y economía política de friedman: una crítica desde el viejo keynesianismo. Investigación Económica, 78 (288), 6.

PAREDES, C. L. 2009. La legislación cooperativa en Guatemala, en Alianza cooperativa Internacional para las Américas 2009. La legislación cooperativa en los países de México, Centroamérica y el Caribe. Disponible en línea: http://www.aciamericas.coop/Situacion-y-diagnostico-de-la [última consulta, marzo 2017].

PÉREZ DE MENDIGUREN, J., \& Etxezarreta, E. 2014. Sobre el concepto de economía social y salidaria: Aproximaciones desde Europa y América Latina . Economía Mundial, 127.

PETIT TORRES, E. E., \& Peña Cedillo, J. 2009. El pensamiento socialista latinoamericano y el desarrollo organizacional: hacia la construcción de alternativas válidas para nuestra región. Opción (59), 5. 
POLO, B. 2001. El Condicionamiento al capital externo como instrumento para la implementación de reformas Neoliberales en América Latina: La aplicación del Consenso de Washington en Argentina . Bogotá: Universidad Mayor de Nuestra Señora del Rosario, Facultad de Relaciones Internacionales.

RAMíREZ, C. A. 1991. El método científico en el psicoanálisis. LX (224), 35.

RESICO, M. 2008. La Economía Social de Mercado Orígenes, relación con la DSI y sus implicancias actuales. Pontificia Universidad Católica de Argentina.

RODRÍGUEZ CARDOSO, L. 2017. «El desarrollo de las ONG de México y su coincidencia con los Objetivos para el Desarrollo Sostenible de Naciones Unidas», CIRIEC-España, Revista de Economía Pública, Social y Cooperativa, núm. 91, 59-84.

ROJAS, J. 2006. Análisis del panorama asociativo presente en el llamado Sector Social de la Economía Mexicana, en Fundación Iberoamericana de la Economía Social-FUNDIBES. La Economía Social en Iberoamérica. Un acercamiento a su realidad, vol. 2, FUNDIBES, España.

SARMIENTO, A. J. 2010. Asuntos fundamentales de la propuesta de reforma a la legislación cooperativa de Colombia. Ponencia $V$ Congreso continental derecho cooperativo, Pontificia Universidad Javeriana, Bogotá, Colombia.

SERVA, M., \& Andión, C. 2006. A economía social no brasil: Panorama de um campo em construção. URALDE, JM La Economia Social Em Iberoamérica: Um Acercamiento a Su Realidad.Madrid: MTAS/FUNDIBES, 39-86.

SOLDEVILLA, E. 1991. Metodología científica de la economía de la empresa. UNED, 1 (3), 19.

STOESSEL, S. 2014. Giro a la izquierda en la América Latina del siglo XXI. Polis Revista Latinoamericana (39), 2.

TENANGO, P. M. 2011. Finanzas Oaxaca. Recuperado el febrero de 2017, de https://www.finanzasoaxaca.gob.mx/pdf/inversion_publica/ pmds/11_13/282.pdf

URBANA GULLI, G. A. 2015. La experiencia de prácticas sociales de la Comisión de Asociados de la filial 030 del Banco Credicoop en la Comunidad de Moreno. Fundación de Educación, Investigación y Asistencia Técnica IDELCOOP, 17.

VALENZUELA, F. J. 2006. Socialismo y marxismo: ¿dos cadáveres? (Regímenes burocrático-autoritarios y marxismo vulgar). Andamios, 3 (5), 1.

VARAS, P. 2014. El caso chileno en torno a la Economía Social de Mercado. En P. R. (SOPLA), Economía Social de Mercado en América Latina Realidad y Desafíos. Chile: Konrad-Adenauer-Stiftung e.V. 


\section{Derechos de autor}

El Boletín de la Asociación Internacional de Derecho Cooperativo es una revista de acceso abierto lo que significa que es de libre acceso en su integridad inmediatamente después de la publicación de cada número. Se permite su lectura, la búsqueda, descarga, distribución y reutilización legal en cualquier tipo de soporte sólo para fines no comerciales y según lo previsto por la ley; sin la previa autorización de la Editorial (Universidad de Deusto) o el autor, siempre que la obra original sea debidamente citada (número, año, páginas y DOI si procede) y cualquier cambio en el original esté claramente indicado.

\section{Copyright}

The International Association of Cooperative Law Journal is an Open Access journal which means that it is free for full and immediate access, reading, search, download, distribution, and lawful reuse in any medium only for non-commercial purposes, without prior permission from the Publisher or the author; provided the original work is properly cited and any changes to the original are clearly indicated. 